\title{
FAKTOR-FAKTOR YANG MEMPENGARUHI KINERJA KEUANGAN DI PERUSAHAAN SUB MACHINERY AND HEAVY EQUIPMENT PADA BEI 2016-2018
}

\section{FACTORS AFFECTING FINANCIAL PERFORMANCE IN SUB MACHINERY AND HEAVY EQUIPMENT COMPANIES IN BEI 2016-2018}

\author{
Mei Sulistiyowati ${ }^{1}$, Yuli Comsatu ${ }^{2}$ \\ 1 Universitas Islam Batik Surakarta - Surakarta \\ Email : meisulistiyowati100599@gmail.com
}

\begin{abstract}
ABSTRAK
Kinerja Keuangan (Financial Performances) ialah gambaran umum keadaan sebuah keuangan perusahaan pada salah satu periode yang mencakup bidang perhimpunan pendanaan. Salah satu tujuan dari penelitian ini adalah untuk mengetahui dan menganalisis bagaimana pengaruh Leverage, Likuditas, Ukuran Perusahaan, ROA terhadap Kinerja Keuangan pada Perusahaan Sub Machinery And Heavy Equipment. Populasi dalam riset ini adalah perusahaan-perusahaan Mesin dan Alat Berat yang tercatat di bursa efek untuk periode 2016-2018 dari BEl. Objek penelitian diatas terdapat ada 22 sampel yang digunakan oleh perusahaan Machinery And Heavy Equipment yang tercatat di BEI. Sumber data yang digunakan dalam penelitian adalah sebuah data sekunder yang terdapat pada Annual Report di BEI. Teknik pengambilan dari sampel menggunakan Purposive Sampling atau teknik pengambilan sampel berdasarkan pertimbangan dan kriteria tertentu. Analisis data dilakukan dengan analisis regresi linier dan pengujian hipotesis menggunakan Uji t dan Uji F. Riset ini dilakukan dengan metode regresi linier berganda untuk analisis sebuah data. Hasil dari penelitian ini memperlihatkan apabila Likuiditas, Ukuran Perusahaan, ROA berpengaruh terhadap Kinerja Keuangan dan Leverage tidak berpengaruh terhadap Kinerja Keuangan.
\end{abstract}

Kata Kunci : Leverage, Likuiditas, Ukuran Perusahaan, ROA, Kinerja Keuangan

\begin{abstract}
ABSTRAC
Financial Performance (Financial Performance) is a general description of the state of a company's finances in one period that includes the field of funding associations. One of the objectives of this research is to find out and analyze how the influence of Leverage, Liquidity, Firm Size, ROA on Financial Performance in Sub Machinery and Heavy Equipment Companies. The population in this research are Machine and Heavy Equipment companies listed on the stock exchange for the 2016-2018 period from the Indonesia Stock Exchange. The object of research above there are 22 samples used by the Machinery and Heavy Equipment company listed on the IDX. The data source used in the study is a secondary data contained in the Annual Report on the IDX. The sampling technique uses Purposive Sampling or sampling techniques based on certain considerations and criteria. Data analysis was performed by linear regression analysis and hypothesis testing using $t$ test and $F$ test. This research was carried out by using multiple linear regression methods for data analysis. The results of this study show that liquidity, company size, $R O A$ affect financial performance and leverage does not affect financial performance.
\end{abstract}

Keywords : Leverage, Liquidity, Firm Size, ROA, Financial Performance. 


\section{PENDAHULUAN}

Kinerja keuangan adalah usaha formal yang telah dilakukan oleh perusahaan yang dapat mengukur keberhasilan suatu perusahaan dalam menghasilkan laba, sehingga dapat melihat prospek, pertumbuhan, dan potensi perkembangan baik perusahaan dengan mengandalkan sumber daya yang ada. Menurut Sartono (2008:257)Leverage adalah penggunaan aset dan sumber dana (source of funds) oleh perusahaan yang memiliki biaya tetap (beban tetap) dengan maksud agar meningkatkan keuntungan potensial pemegang saham. Menurut Kasmir (2012:128) Likuiditas adalah kemampuan perusahaan dalam memenuhi kewajiban jangka pendeknya. Pengertian lain adalah kemampuan seseorang atau perusahaan untuk memenuhi kewajiban atau utang yang segera harus dibayar dengan harta lancarnya. Brown (2009), Menyatakan bahwa Ukuran perusahaan mengacu pada bagaimana perusahaan besar atau kecil adalah tindakan berdasarkan nilai pasar perusahaan. Oleh karena itu, ukuran perusahaan dapat disimpulkan sebagai seberapa besar sebuah perusahaan tercermin total aset, penjualan, atau kapitalisasi pasar. Menurut Brigham dan Houston (2001:90), "Rasio laba bersih terhadap total aktiva mengukur pengembalian atas total aktiva (ROA) setelah bunga dan pajak".

Adapun tujuan dan manfaat penelitian untuk mengetahui dan meganilisi bagaimana pengaruh Leverage terhadap kinerja keuangan pada perusahaan sub macginery and heavy equipment. Untuk mengetahui dan menganalisis bagaimana pengaruh likuiditas terhadap kinerja keuangan pada perusahaan sub macginery and heavy equipment. Untuk mengetahui dan menganalisis bagaimana pengaruh firm size terhadap kinerja keuangan pada perusahaan sub macginery and heavy equipment. Untuk mengetahui dan menganalisis bagaimana pengaruh $R O A$ terhadap kinerja keuangan pada perusahaan sub macginery and heavy equipment.

\section{LANDASAN TEORI}

\section{Teori Tradeoff}

Menurut teori tradeoff, pembiayaan optimum campuran bertepatan dengan tingkat leverage keuangan di mana manfaat dan biaya dari pembiayaan utang yang tepat seimbang. Penggunaan utang akan memiliki efek ini hanya jika tingkat pengembalian investasi atau aset lebih besar dari tingkat pengembalian utang (Watkins, 2002)

\section{Teori Legitimasi (Legitimacy Theory)}

Teori legitimasi secara eksplisit dikatakan oleh Nor Hadi (2011:87) adalah mengakui bahwa bisnis dibatasi oleh kontrak sosial yang menyebutkan bahwa perusahaan sepakat untuk menunjukkan berbagai aktivitas sosial perusahaan agar perusahaan memperoleh penerimaan masyarakat akan tujuan perusahaan yang pada akhirnya akan menjamin kelangsungan hidup perusahaan.

\section{Teori Kontrak Sosial (Sosial Contract Theory)}

Menurut Nor Hadi (2011:95) kontrak sosial muncul karena adanya interelasi dalam kehidupan sosial masyarakat, agar terjadi keselarasan, keserasian dan keseimbangan, termasuk terhadap lingkungan. Agar terjadi keseimbangan (equality), maka perlu kontrak sosial baik secara eksplisit maupun implisit sehingga terjadi kesepakatan-kesepakatan yang saling melindungi kepentingannya. 


\section{Leverage}

Leverage adalah penggunaan aset dan sumber dana (source of funds) oleh perusahaan yang memiliki biaya tetap (beban tetap) dengan maksud agar meningkatkan keuntungan potensial pemegang saham (Sartono, 2008:257)

\section{Liquidity}

Likuiditas adalah kemampuan perusahaan dalam memenuhi kewajiban jangka pendeknya. Pengertian lain adalah kemampuan seseorang atau perusahaan untuk memenuhi kewajiban atau utang yang segera harus dibayar dengan harta lancarnya. Menurut Kasmir (2012:128), ketidakmampuan perusahaan membayar kewajibannya terutama jangka pendek (yang sudah jatuh tempo) disebabkan oleh berbagai faktor, yaitu:

1. Bisa dikarenakan memang perusahaan sedang tidak memiliki dana sama sekali, atau

2. Bisa mungkin saja perusahaan memiliki dana, namun saat jatuh tempo perusahaan tidak memiliki dana (tidak cukup dana secara tunai sehingga harus menunggu dalam waktu tertentu, untuk mencairkan aktiva lainnya seperti menagih piutang, menjual surat-surat berharga, atau menjual sediaan atau aktiva lainnya).

\section{Firm Size}

Menurut Brigham \& Houston (2010:4) ukuran perusahaan adalah sebagai berikut :

"Ukuran perusahaan merupakan ukuran besar kecilnya sebuah perusahaan yang ditunjukan atau dinilai oleh total asset, total penjualan, jumlah laba, beban pajak dan lainlain".

Menurut Vieira (2010), Size mempengaruhi perusahaan-perusahaan kecil (diukur dengan total aktiva atau total kapitalisasi) cenderung keluar-melakukan pasar bahkan ketika kembali disesuaikan untuk risiko. Brown (2009), Menyatakan bahwa Ukuran perusahaan mengacu pada bagaimana perusahaan besar atau kecil adalah tindakan berdasarkan nilai pasar perusahaan. Oleh karena itu, ukuran perusahaan dapat disimpulkan sebagai seberapa besar sebuah perusahaan tercermin total aset, penjualan, atau kapitalisasi pasar.

\section{ROA}

Return on Assets (ROA) merupakan salah satu rasio profitabilitas Dalam analisis laporan keuangan, rasio ini paling sering disoroti, karena mampu menunjukkan keberhasilan perusahaan menghasilkan keuntungan. ROA mampu mengukur kemampuan perusahaan manghasilkan keuntungan pada masa lampau untuk kemudian diproyeksikan di masa yang akan datang. Assets atau aktiva yang dimaksud adalah keseluruhan harta perusahaan, yang diperoleh dari modal sendiri maupun dari modal asing yang telah diubah perusahaan menjadi aktiva-aktiva perusahaan yang digunakan untuk kelangsungan hidup perusahaan. Menurut Brigham dan Houston (2001:90), "Rasio laba bersih terhadap total aktiva mengukur pengembalian atas total aktiva (ROA) setelah bunga dan pajak". 


\section{Pengembangan Hipotesis}

\section{Pengaruh Leverage terhadap Kinerja Kauangan}

Leverage Keuangan(Financial Leverage) secara Signifikan dan Negatif mempengaruhi Kinerja Keuangan(Ismail bishar mohamed (2016)).

H1 : Leverage berpengaruhi terhadap Kinerja Keuangan

\section{Pengaruh Likuiditas terhadap Kinerja Keuangan}

Penelitian oleh Tahir, M. (2016) di Pakistan pada sektor perbankan menunjukkan dampak positif likuiditas terhadap kinerja keuangan perusahaan di berbagai negara, sektor ekonomi dan periode yang berbeda.

H2 : Likuiditas berpengaruhi terhadap Kinerja Keuangan

\section{Pengaruh Firm Size terhadap Kinerja Keuangan}

Penelitian oleh Omondi \& Muturi (2013) menunjukkan bahwa ukuran perusahaan memiliki pengaruh positif yang signifikan pada kinerja keuangan.

H3 : Firm Size berpengaruhi terhadap Kinerja Keuangan

\section{Pengaruh ROA terhadap Kinerja Keuangan}

Penelitian oleh Kasman \& Carvallo (2013) menunjukkan bahwa ada pengaruh yang signifikan positif dari efisiensi dan resiko terhadap kinerja perbankan yang diukur dengan return on asset (ROA).

H4 : ROA berpengaruhi terhadap Kinerja Keuangan

\section{METODELOGI PENELITIAN}

\section{Jenis dan Sumber Data Penelitian}

Jenis penelitian ini ialah penelitian asosiatif kausal. Jenis data yang digunakan dalam penelitian ini adalah data sekunder, yaitu berupa laporan keuangan tahunan. Data yang diperoleh dari perusahaan Sub Machinery And Heavy Equipment yang terdaftar di Bursa Efek Indonesia yang berupa angka-angka sehingga dapat diolah dan dianalisis menggunakan metode regresi sehingga dapat diketahui hasilnya.Populasi yang digunakan dalam penelitian ini adalah semua Perusahaan Sub Machinery And Heavy Equipment tahun 2016-2018. Pengambilan sampel dilakukan dengan metode purposive sampling. Sampel perusahaan yang berhasil diperoleh dalam penelitian ini sebanyak 22 perusahaan dengan total 50 data.

\section{Metode Analisis dan Hipotesisi Penelitian}

Pengujian pertama dengan uji statistik deskriptif, Kemudian pengujian asumsi klasik sebagai salah satu syarat untuk bisa menggunakan persamaan regresi berganda adalah terpenuhinya uji asumsi klasik. 


\section{Variabel dan Pengukuran}

\section{Dependen}

Variabel ini dihitung menggunakan rumus :
Kinerja Keuangan
(Profitabilitas)

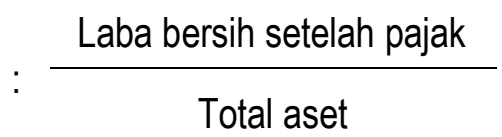

\section{Independen}

\section{Leverage}

Menurut (Sartono, 2008:257) penggunaan aset dan sumber dana (source of funds) oleh perusahaan yang memiliki biaya tetap (beban tetap) dengan maksud agar meningkatkan keuntungan potensial pemegang saham. Variabel ini bisa diukur dengan menggunakan rumus :

Leverage $(\mathrm{CR}) \quad=\frac{\text { Total Liabilities }}{\text { Equitas(Modal) }}$

\section{Likuidity}

Menurut Kasmir (2012:128), ketidakmampuan perusahaan membayar kewajibannya terutama jangka pendek (yang sudah jatuh tempo) disebabkan oleh berbagai faktor. Variabel ini bisa diukur dengan menggunakan rumus :

Likuiditas $\quad=\frac{\text { Total Aset }}{\text { Liabilities Jk Pendek (current liabilities) }}$

\section{Firm Size}

Menurut Brown (2009), Menyatakan bahwa Ukuran perusahaan mengacu pada bagaimana perusahaan besar atau kecil adalah tindakan berdasarkan nilai pasar perusahaan. Oleh karena itu, ukuran perusahaan dapat disimpulkan sebagai seberapa besar sebuah perusahaan tercermin total aset, penjualan, atau kapitalisasi pasar. Variabel ini bisa diukur dengan menggunakan rumus :

Ukuran Perusahaan

(Firm Size)

$$
=\operatorname{Ln}(\text { Total Aset })
$$

ROA

Menurut Brigham dan Houston (2001:90), "Rasio laba bersih terhadap total aktiva mengukur pengembalian atas total aktiva (ROA) setelah bunga dan pajak". Variabel ini bisa diukur dengan menggunakan rumus :

ROA $=\frac{\text { Laba Sebelum Pajak }}{\text { Total Aset }}$

\section{HASIL DAN PEMBAHASAN \\ Hasil Penelitian \\ Analisis Statistik Deskriptif}


Statistik deskriptif memberikan gambaran atau deskripsi suatu data yang dilihat dari nilai minimum, maksimum, rata-rata (mean), standar deviasi.Untuk memberikan gambaran analisis statistik deskriptif dalam penelitian ini ditunjukkan sebagai berikut:

\begin{tabular}{lrrrrr}
\hline & N & Minimum & Ma,fximum & \multicolumn{1}{c}{ Mean } & Std. Deviation \\
\hline LVR & 66 &, 01 & 1818573,02 & 41258,5631 & $2,38904 E 5$ \\
LKD & 66 &, 00 & 73,86 & 6,7734 & 12,27334 \\
FSZ & 66 & 8,59 & 30,68 & 22,8224 & 5,96910 \\
ROA & 66 &, 00 & 215,91 & 7,6671 & 37,08989 \\
KK & 66 &, 00 & 55140,79 & 1484,0534 & 8502,46724 \\
Valid N & 66 & & & & \\
(listwise) & & & & & \\
\hline
\end{tabular}

Dari output diatas dapat dilihat bahwa untuk variable LVR, jumlah data $(\mathrm{N})$ adalah 66 , biaya minimum Rp ,01 biaya maksimum Rp 1818573,02 biaya rata-rata $R p$ 41258,5631, dan standar deviasi adalah Rp 238.904. Untuk variable LKD, jumlah data (N) adalah 66 , biaya minimum Rp ,00 biaya maksimum $\mathrm{Rp} \mathrm{73,86}$ biaya rata-rata $\mathrm{Rp} 6,7734$, dan standar deviasi adalah $\mathrm{Rp}$ 12,27334. Untuk variable FSZ, jumlah data $(\mathrm{N})$ adalah 66 , biaya minimum $\mathrm{Rp} 8,59$ biaya maksimum Rp 30,68 biaya rata-rata $\mathrm{Rp} 22,8224$, dan standar deviasi adalah Rp 5,96910. Untuk variable ROA, jumlah data $(\mathrm{N})$ adalah 66 , biaya minimum $\mathrm{Rp}, 00$ biaya maksimum $\mathrm{Rp} 215,91$ biaya rata-rata $\mathrm{Rp} 7,6671$, dan standar deviasi adalah $\mathrm{Rp} 37,08989$.

\section{Uji Asumsi Klasik}

Uji Normalitas Residual digunakan untuk menguji apakah nilai residual yang dihasilkan dari regresi terdistribusi secara normal atau tidak. Metode yang digunakan adalah metode grafik, yaitu dengan melihat penyebaran data pada 19 sumber diagonal pada grafik normal $P$ - $P$ plotof regresion of standardized. Sebagai dasar pengambilan keputusannya, jika titik- titik menyebar sekitar garis dab mengikuti garis diagonal, maka nilai residual tersebut telah normal (Priyatno, 2014).

\begin{tabular}{llll}
\hline & $\begin{array}{l}\text { Unstandardized } \\
\text { Residual }\end{array}$ & Standar & Keterangan \\
\hline Asymp. Sig. (2-tailed) & ,249 & $>0.05$ & Normal \\
\hline
\end{tabular}

Dari output diatas dapat diketahui nilai Asymp. Sig ,249 lebih besar dari 0,05. Sehingga dapat disimpulkan bahwa model regresi terdistribusi secara normal.

\section{Uji Regresi Linier Berganda}

\begin{tabular}{lllllr} 
& \multicolumn{5}{c}{ Uji F } \\
\hline Model & $F$ & Sig & Syarat & Keterangan & \\
\hline Regression & 2,831 &, $036^{\mathrm{a}}$ & $<0,05$ & ROA, LVR, FSZ, LKD mempunyai \\
& & & $\begin{array}{l}\text { pengaruh secara simultan terhadap Kinerja } \\
\text { Keuangan. }\end{array}$
\end{tabular}


Dari output diatas menunjukkan bahwa $F$ hitung $>$ dari $F$ tabel dan nilai sig $<0,05$ yang artinya bahwa ROA, LVR, FSZ, LKD mempunyai pengaruh secara simultan terhadap Kinerja Keuangan.

\begin{tabular}{llllll}
\multicolumn{5}{c}{ Uji T } \\
\hline Hipotesis & T hitung & T tabel & Sig & Syarat & Keterangan \\
\hline LVR & $-2,504$ & 2,388 &, 016 & $<0,05$ & Di Terima \\
LKD &,- 553 & 2,388 &, 583 & $<0,05$ & Di Tolak \\
FSZ & $-1,926$ & 2,388 &, 061 & $<0,05$ & Di Tolak \\
ROA &,- 282 & 2,388 &, 780 & $<0,05$ & Di Tolak \\
\hline
\end{tabular}

Berdasarkan hasil uji t disajikan pada tabel 5.1 bahwa niai $\beta$ dengan signifikansi uji t menunjukan angka lebih lebih kecil dari taraf nyata dalam penelitian ini yaitu 0,05 . Hal ini menunjukkan variabel Pengalaman Audit berpengaruh terhadap Kualitas Audit. Dengan demikian hipotesis H4 diterima.

\section{Rekomendasi Kebijakan}

\section{Rekomendasi}

1. Penelitian ini hanya terbatas untuk perusahaan sub Machinery And Heavy Equipment tahun 2016-2018.

2. Data yang digunakan adalah data sekunder yang mungkin terdapat kesalahan dalam Kebijakan memasukkan data yang berupa angka-angka.

1. Peneliti selanjutnya bisa menggunakan perusahaan di sektor selain sektor pada penelitian ini.

2. Peneliti selanjutnya sebaiknya menambah variabel yang berpengaruh terhadap Kinerja Keuangan agar hasil koefisien determinasinya lebih baik daripada hasil penelitian ini.

Peneliti selanjutnya diharapkan lebih teliti dalam memasukkan data agar mengurangi resiko data outlier terlalu banyak. 


\section{DA FTAR PUSTAKA}

Dogan, M. (2013). Apakah ukuran perusahaan mempengaruhi profitabilitas perusahaan? Bukti dari Turki. Jurnal Keuangan dan Akuntansi, 4 (4), hlm 53-59.

Mahmoudi, S., (2014). Pengaruh Leverage pada Profitabilitas Industri Semen. Reef Resources Assessment dan Manajemen Teknis Kertas, Vol. 40, 2014, hlm 673-676.

Mouhammed, AJ, Waheed, A. (2016). "Ukuran Firm sebagai Moderator untuk leverage-Kinerja Hubungan: Sebuah Muncul Market Review. Jurnal Kemiskinan, Investasi dan Pembangunan, 23, 2016. Moyer, RC, McGiugan, JR, \& Kretlow, WJ (1999).

Tsuji, C., (2013). Profitabilitas perusahaan dan Struktur Modal: Kasus Perusahaan Industri Mesin dari Tokyo Stock Exchange. International Journal of Business Administration, Vol. 4, No.3, pp 14-21.

Abbasi A. \& Malik, T. A (2015) "Perusahaan Ukuran Kinerja Keuangan Moderating dalam Tumbuh perusahaan: Sebuah Bukti Empiris dari Pakistan. International Journal Ekonomi dan Keuangan Masalah 2015, 5 (2), 334-339.

Ali, SA (2015). Pengaruh pengelolaan likuiditas terhadap profitabilitas di Yordania Bank komersial. jurnal internasional bisnis dan manajemen. Vol. 10, No. 1.

Tersedia di: http: //ro.uow.edu.au/aabfj/vol5/iss3/8 Durrah, O. dkk (2016). Menjelajahi Hubungan antara Rasio dan Indikator Likuiditas Kinerja Keuangan. Sebuah Studi Analitis Pangan Perusahaan Industri Terdaftar di Amman Bursa" International Journal Ekonomi dan Isu Keuangan, 2016, 6 (2), 435-441.

Ehiedu, VC (2014) limpact likuiditas pada profitabilitas beberapa perusahaan yang dipilih. penelitian jurnal keuangan dan akuntansi.

Inyiama1 \& Chukwuani (2014)"empiris Investigasi Interaksi antara Firm Ukuran dan Kinerja Keuangan Perusahaan: Sebuah Studi Berdasarkan Brewery Sektor Nigeria"Journal of Finance dan Bank Manajemen Desember 2014, Vol. 2, No 3 \& . 4, pp 53-68 ISSN: 23336064.

Kartal Demirgüneş (2016)"Pengaruh Likuiditas terhadap Kinerja Keuangan: Bukti TURKI Retai IIndustry"International Journal Ekonomi dan Keuangan; Vol. 8, No. 4; 2016 ISSN 1916971X E-ISSN 1916-9728.

Khidmat, W. \& Rehman, M. (2014) Dampak Likuiditas \& Solvabilitas pada Profitabilitas Sektor Kimia Pakistan. Ekonomica manajemen ekonomi inovasi innovance EMI, Vol. 6, Edisi 3, 2014 ISSN: 1804-1299 (Print), 1805-353X (Online) I SSN: 2455-6114.

Khodamipou, A. Golestan, S. \& Khorrami, M. (2013)"Hubungan antara likuiditas dan ukuran perusahaan dengan nilai perusahaan pada perusahaan yang terdaftar di Bursa Efek Teheran”jurnal online Eropa ilmu alam dan ilmu sosial 2013, vol.2 No.3 (s) pp 12101217.

Mengesha, W. (2014). Dampak Manajemen Modal Kerja terhadap Kinerja Perusahaan: The Kasus Terpilih Logam Perusahaan Manufaktur di Addis Ababa, Ethiopia. Jimma Universitas kuliah bisnis dan ekonomi jurusan akuntansi dan keuangan.

Muhammad, U. (2014) .Determinant dari komersial profitabilitas bank dari jurnal PakistanInternational akuntansi dan pelaporan keuangan .Vol. 4, No 2.

Odalo, Achoki \& Njuguna (2016). Berkaitan Ukuran Perusahaan dan Kinerja Keuangan di Perusahaan pertanian Terdaftar di Bursa Efek Nairobi di Kenya. International Journal Ekonomi dan Keuangan; Vol. 8, No. 9; 2016 ISSN 1916-971X E-ISSN 1916-9728. 